\title{
Five Centimeters Morton's Neuroma in a 46- Year-Old Woman Affected by Macrodactily
}

\author{
Francesco Di Caprio ${ }^{1}$ Renato Meringolo ${ }^{2}$ Maria Adiletta Navarra ${ }^{2}$ Massimiliano Mosca ${ }^{3}$ \\ Lorenzo Ponziani ${ }^{1}$ \\ ${ }^{1}$ Operating Unit of Orthopedics and Traumatology, Istituto per la \\ Sicurezza Sociale di San Marino, San Marino, Italy \\ 2 AUSL of Romagna, Operating Unit of Orthopedics and Traumatology, \\ Ceccarini Hospital, Riccione, Italy \\ ${ }^{3}$ First Orthopedics and Traumatology Clinic, Rizzoli Orthopedic \\ Address for correspondence Francesco Di Caprio, MD, U.O. \\ Ortopedia e Traumatologia, Istituto per la Sicurezza Sociale di San \\ Marino, Via Scialoja 20, 47893 Cailungo, San Marino, Italy \\ (e-mail: fra.dicaprio@gmail.com).
} Institute, Bologna, Italy

Joints 2019;7:127-130.

\begin{abstract}
The present article described the case of a voluminous Morton's neuroma of the third intermetatarsal space in a patient affected by macrodactily. The case was unique because of its dimensions, the uncommon surgical approach which was needed for removal, the association with macrodactily of the fourth toe with Raynaud's phenomenon, and the postoperative defect in the intrinsic muscles. The patient was operated in February 2016 by transverse plantar approach. Twelve months after surgery, the patient complained for hypoesthesia on third and fourth toes with inability to actively spread the toes and enlargement in the second interdigital space. The dimensions of the lesions may be explained with the presence of macrodactily in the fourth toe with occasional Raynaud's phenomenon, which may have caused an abnormal arrangement of the nerve branches for

\section{Keywords}

- Morton

- foot

- neuroma

- macrodactily

- Raynaud the fourth interspace with related microtrauma. A plantar approach was highly recommended as the size of the lesion forced it to the plantar surface of the foot. The inability to actively spread the toes and the enlargement of the second interdigital space are likely to be related to a deficiency of the interosseous muscles, innervated by the deep branch of the lateral plantar nerve, which had probably been sacrificed because of the size of the lesion and the subversion of the surrounding anatomical relationships.
\end{abstract}

\section{Introduction}

Morton's neuroma is a very common cause of metatarsalgia, and consists in an interdigital nerve disease of the foot, classically located at the third intermetatarsal space. ${ }^{1}$

It was suggested that the common digital nerve to the third interspace is thicker than the others, as it results from an anastomosis between branches from the two nerve trunks. ${ }^{2-4}$ Another anatomical factor is the increased mobility of the fourth radius (moving on the cuboid), compared with the third (fixed to the cuneiform). Some believe that taut distal metatarsal transverse ligament plays a critical role in compressing the interdigital nerve. ${ }^{5}$

A longitudinal dorsal approach centered on the interspace is the preferred choice by most surgeons. The advantages of a dorsal approach ${ }^{5,6}$ as compared with plantar approach are described as the ability to release the intermetatarsal ligament; the incision being in the nonweight bearing surface of the foot, allowing for early rehabilitation; good overview as to follow the nerve proximally; and the plantar cutaneous nerves are easier to find and excise. received

September 15, 2017

accepted after revision

April 13, 2020

published online

May 20, 2020
DOI https://doi.org/

$10.1055 / \mathrm{s}-0040-1712112$.

ISSN 2282-4324.

\footnotetext{
(C) 2020. The Author(s).

This is an open access article published by Thieme under the terms of the Creative Commons Attribution-NonDerivative-NonCommercial-License, permitting copying and reproduction so long as the original work is given appropriate credit. Contents may not be used for commercial purposes, or adapted, remixed, transformed or built upon. (https://creativecommons.org/ licenses/by-nc-nd/4.0/) Georg Thieme Verlag KG, Rüdigerstraße 14, 70469 Stuttgart, Germany
} 
The advocates of plantar approach believe that this approach is safe, and that there is no need to release the deep transverse ligament. ${ }^{6,7}$ A longitudinal plantar approach must be performed exactly below the intermetatarsal space and thorough with resolution through the fat pad to prevent the dissection. ${ }^{8,9}$ It is possible to perform a transverse plantar approach just proximal to the flexion skin fold. ${ }^{10,11}$ This prevents approach to the load portion, but it must be extended to the adjacent spaces, with significant dissection, possible atrophy of the fat pad, and difficulty following the nerve proximally. ${ }^{5}$

Postoperative wound infection, hematoma, and scar problems were significantly higher in patients having plantar approach. $^{8}$

A hypoesthesia or numbness in the supplying area of the resected nerve was detected in $72 \%$ of the feet. The pattern of numbness was quite variable and it was bothersome in a limited percentage of cases (17\%). ${ }^{6}$ Sometimes the residual discomfort is described as the feeling of walking on cotton, or to have jammed sock under the foot.

The present case regards a 46 years old woman affected by a voluminous neuroma in the third webspace, pushed toward the plantar surface of the foot. It was a unique case because of various aspects: its dimensions, the uncommon surgical approach which was needed for removal, the association with macrodactily of the fourth toe with Raynaud's phenomenon, and the postoperative defect in the intrinsic muscles. After a detailed case presentation, all these aspects will be discussed.

\section{Case Presentation}

A 46-year-old woman came to our attention complaining of a painful swelling in the plantar aspect of the foot, just beneath the metatarsal heads. The pain was present for 3 years. At the time of the appearance of pain, the swelling had already grown to final dimensions.

The patient complained of morning pain, and feeling of hardening under the foot, which then was relieved during the day. Then sudden sharp pain preceded by numbness at the toes. When wearing closed shoes, she had to take them off and massage her foot to reverse the pain.

At physical examination, a macrodactily of the fourth toe was noted, and the X-rays revealed no bone deformities. The patient reported occasional Raynaud's phenomenon. The patient reported no significant medical history and no allergies, and she did not take drugs.

She was operated in February 2016 for mass excision and histological examination. The patient was positioned supine on the operating table, with a tourniquet at the proximal thigh. Surgical approach was performed through a plantar transverse incision just proximal to the flexion skin fold, from the fourth to the second intermetatarsal space (-Fig. 1). The mass was directly retrievable under the skin, and the dissection revealed its nervous nature. The lesion was in continuation of the common digital nerve for the third space, and distally it bifurcated in the two digital nerves.

The lesion was excised trying to follow the common digital nerve proximally and to isolate the two digital nerves

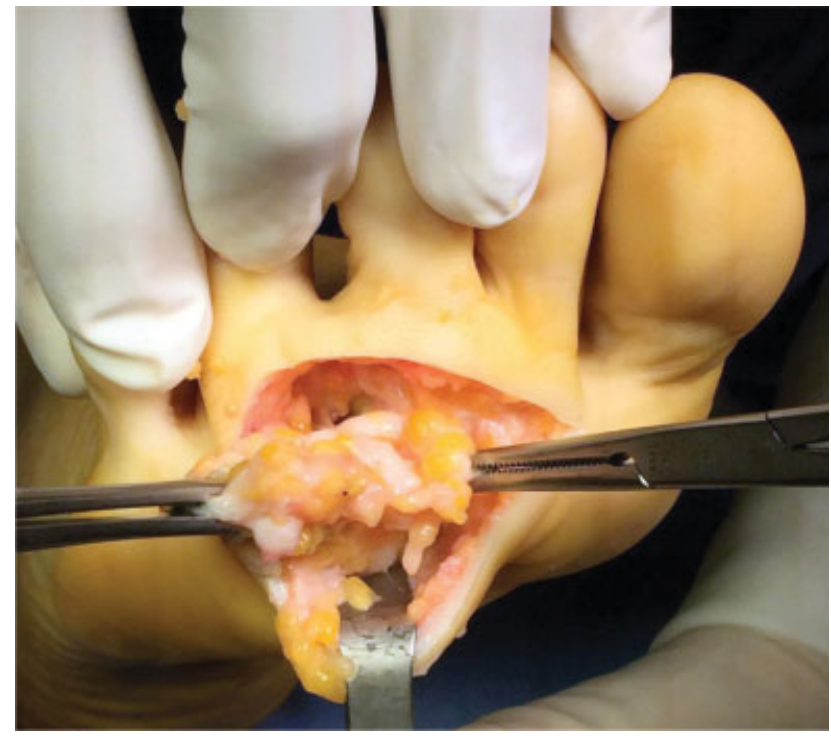

Fig. 1 Dissection of the lesion through a plantar transverse approach.

distally. At final examination, the lesion was yellowish and tender and it was measured out to be $5 \times 3 \mathrm{~cm}$ (-Fig. 2 ).

Histological examination revealed a fibrous tissue with poor cellular component and various nerve trunks at the periphery, interspersed with fibrosis. The score sheet indicated a Morton's neuroma.

After the operation, the patient had a compressive bandage, and she was discharged the day after operation, walking with postoperative shoe for 15 days, only for short periods. The bandage was maintained for 7 days, and then a simple medication was performed. Suture was removed after 15 days: the wound was closed with subcutaneous hematoma. Gradually she was allowed to wear a normal shoe.

Six and 12 months after the surgery, the patient was revised: the surgical wound was perfectly healed (-Fig. 3), with no fat pad atrophy, subcutaneous adhesions, or calluses. The patient could walk with every kind of footwear and without any plantar discomfort. But she complained for hypoesthesia on the third and fourth toes, with inability to actively spread the toes and enlargement in the second interdigital space (-Fig. 4).

\section{Discussion}

Morton's neuroma is a very common forefoot disease. Its dimensions are variable, but usually they are of 5 to $10 \mathrm{~mm} .{ }^{12,13}$ Even small lesions, however, may be symptomatic, and in this case are even more difficult to diagnose. ${ }^{14}$

A neuroma of this size $(5 \mathrm{~cm})$ had never been reported in the literature, and probably represents an exception, as its etiology differs from classic Morton's neuroma. The presence of a deformity of the fourth toe (macrodactily), without bone involvement, with occasional Raynaud's phenomenon, may have caused an abnormal arrangement of the nerve branches for the fourth interspace with related microtrauma.

In this case, a plantar approach was highly recommended as the size of the lesion forced it to the plantar surface of the foot, becoming palpable beneath the skin. The transverse 


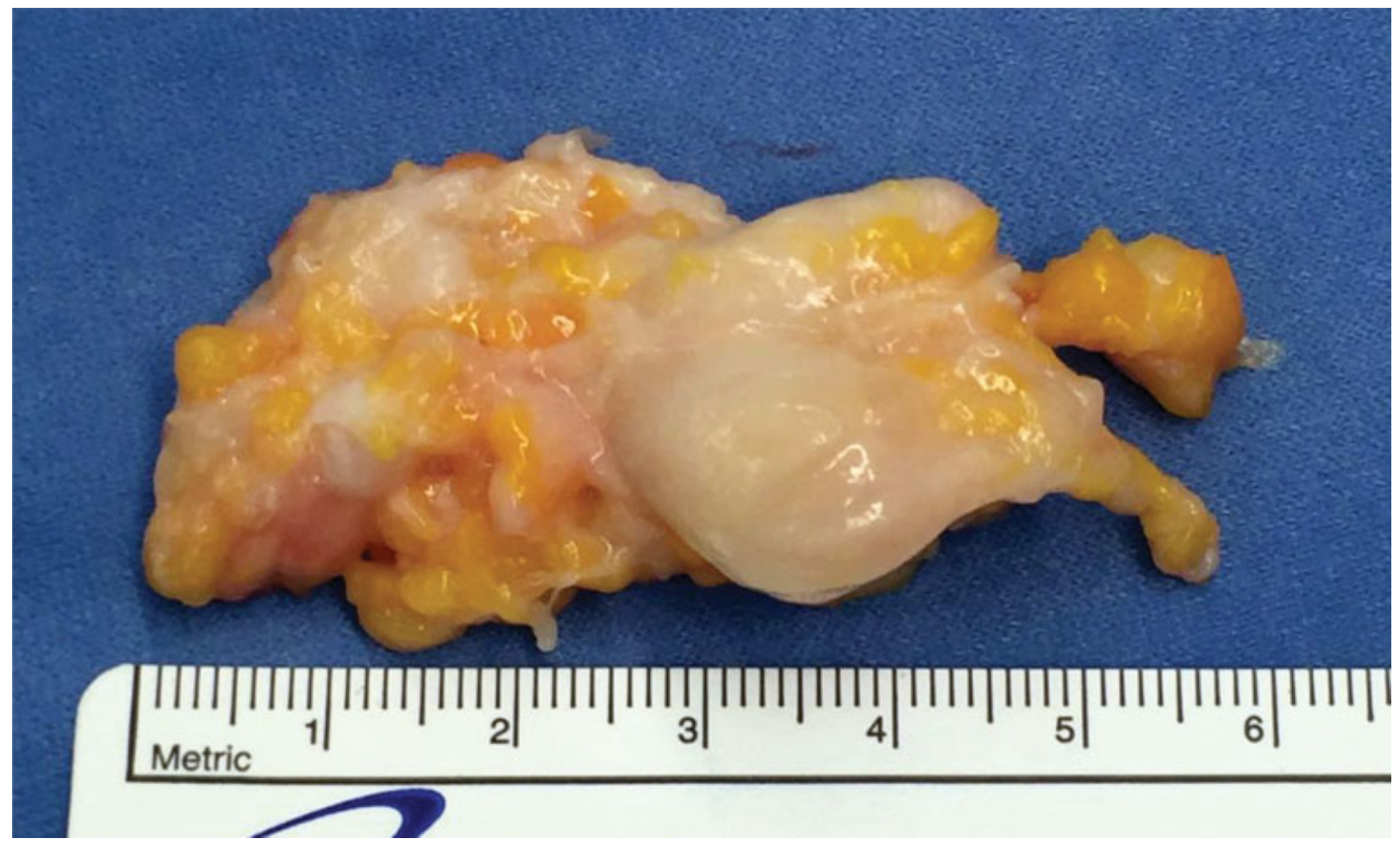

Fig. 2 The lesion was removed including bifurcation into the two digital nerves, and measured.

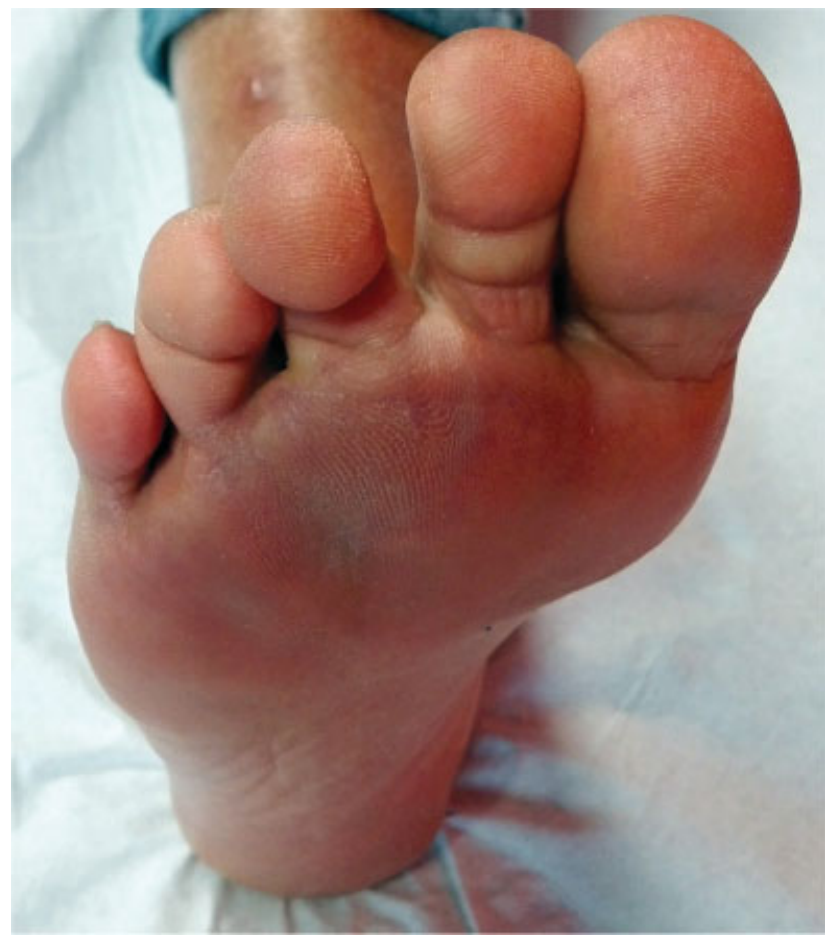

Fig. 3 The surgical wound 6 months after operation was perfectly healed, and no calluses were evident.

incision allowed us to have enough exposure for accurate dissection of the neuroma and its removal.

Twelve months after surgery, the patient had no wound problems related to plantar approach. The inability to actively spread the toes and the enlargement of the second interdigital

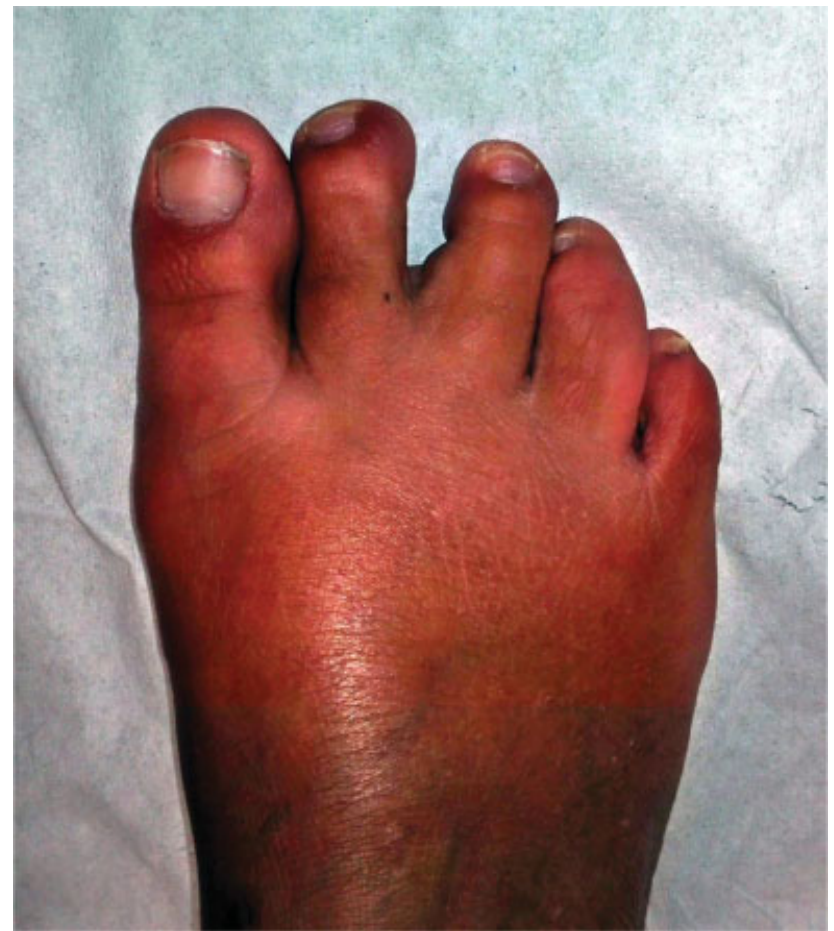

Fig. 4 The bearing foot showed an enlargement in the second interdigital space.

space are likely to be related to a deficiency of the interosseous muscles, which are innervated by the deep branch of the lateral plantar nerve, which had probably been sacrificed because of the size of the lesion and the subversion of the surrounding anatomical relationships. 
130 Five Centimeters Morton's Neuroma in a 46-Year-Old Woman Affected by Macrodactily Di Caprio et al.

An abnormal arrangement of the nerve branches should be considered when a Morton's neuroma is associated with forefoot deformities.

\section{Conflict of Interest}

None declared.

\section{References}

1 Di Caprio F, Meringolo R, Shehab Eddine M, Ponziani L. Morton's interdigital neuroma of the foot: a literature review. Foot Ankle Surg 2018;24(02):92-98

2 Jones JR, Klenerman L. A study of the communicating branch between the medial and lateral plantar nerves. Foot Ankle 1984;4 (06):313-315

3 Diez EM, Mas SM, Pi JF, Aramburo F. Comparative results of two different techniques in the treatment of the Morton's neuroma. Foot 1999;9(03):134-137

4 Bennett GL, Graham CE, Mauldin DM. Morton's interdigital neuroma: a comprehensive treatment protocol. Foot Ankle Int 1995; 16(12):760-763

5 Alexander IJ, Johnson KA, Parr JW. Morton's neuroma: a review of recent concepts. Orthopedics 1987;10(01):103-106
6 Faraj AA, Hosur A. The outcome after using two different approaches for excision of Morton's neuroma. Chin Med J (Engl) 2010;123(16):2195-2198

7 Quinn TJ, Jacobson JA, Craig JG, van Holsbeeck MT. Sonography of Morton's neuromas. AJR Am J Roentgenol 2000;174(06):1723-1728

8 Kundert HP, Plaass C, Stukenborg-Colsman C, Waizy H. Excision of Morton's neuroma using a longitudinal plantar approach: a midterm follow-up study. Foot Ankle Spec 2016;9(01):37-42

9 Richardson DR, Dean EM. The recurrent Morton neuroma: what now? Foot Ankle Clin 2014;19(03):437-449

10 Nery C, Raduan F, Del Buono A, Asaumi ID, Maffulli N. Plantar approach for excision of a Morton neuroma: a long-term followup study. J Bone Joint Surg Am 2012;94(07):654-658

11 Glasoe WM, Coughlin MJ. A critical analysis of Dudley Morton's concept of disordered foot function. J Foot Ankle Surg 2006;45 (03):147-155

12 Makki D, Haddad BZ, Mahmood Z, Shahid MS, Pathak S, Garnham I. Efficacy of corticosteroid injection versus size of plantar interdigital neuroma. Foot Ankle Int 2012;33(09):722-726

13 Mahadevan D, Venkatesan M, Bhatt R, Bhatia M. Diagnostic accuracy of clinical tests for Morton's neuroma compared with ultrasonography. J Foot Ankle Surg 2015;54(04):549-553

14 Sharp RJ, Wade CM, Hennessy MS, Saxby TS. The role of MRI and ultrasound imaging in Morton's neuroma and the effect of size of lesion on symptoms. J Bone Joint Surg Br 2003;85(07):999-1005 